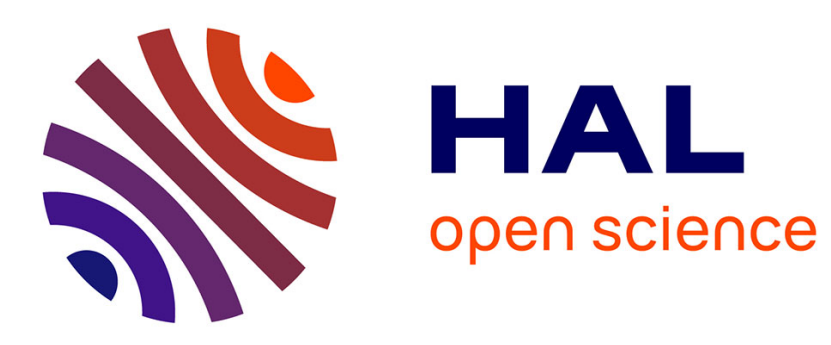

\title{
Work performance and mental workload in multiple talker environments
}

\author{
Ange Ebissou, Patrick Chevret, Etienne Parizet
}

\section{To cite this version:}

Ange Ebissou, Patrick Chevret, Etienne Parizet. Work performance and mental workload in multiple talker environments. International Congress on Acoustics 2013, 2013, Montréal, Canada. 4pNSa8. hal-00994681

\section{HAL Id: hal-00994681 \\ https://hal.science/hal-00994681}

Submitted on 21 May 2014

HAL is a multi-disciplinary open access archive for the deposit and dissemination of scientific research documents, whether they are published or not. The documents may come from teaching and research institutions in France or abroad, or from public or private research centers.
L'archive ouverte pluridisciplinaire HAL, est destinée au dépôt et à la diffusion de documents scientifiques de niveau recherche, publiés ou non, émanant des établissements d'enseignement et de recherche français ou étrangers, des laboratoires publics ou privés. 


\section{Proceedings of Meetings on Acoustics}
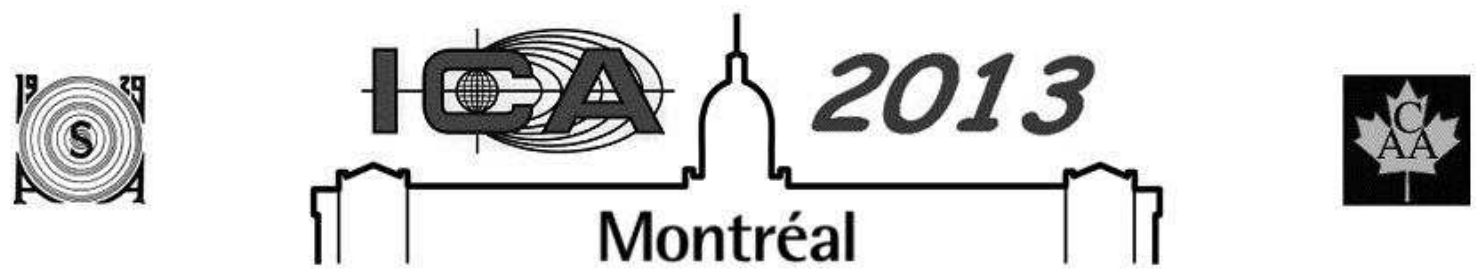

ICA 2013 Montreal

Montreal, Canada

2 - 7 June 2013

Noise

Session 4pNSa: Effects of Noise on Human Performance and Comfort II

\section{4pNSa8. Work performance and mental workload in multiple talker environments}

Ange Ebissou*, Patrick Chevret and Etienne Parizet

*Corresponding author's address: Institut National de Recherche et de Sécurité (INRS), 1 rue du Morvan, Vandoeuvre cedex, 54519, --, France, ange.ebissou@inrs.fr

The impairment of cognitive performance resulting from the presence of speech sounds is known to increase as the intelligibility of the speech signals is improved. For that reason, speech intelligibility measures are used to quantify the nuisance potential of an unattended voice. However, most of these indexes struggle with situations in which the level of the masking sound is fluctuating. This is the case in open-plan offices, where competing voices are involved. This paper relates a set of experiments in which subjects had to carry out a basic memory task in various office-like noise settings. In addition to a target speech, the masking sounds were made up of speech and differed in level or temporal variability. Disturbance was assessed both through objective measurements of performance and subjective reports of workload. The results highlight the importance of taking into account the temporal fluctuations of the overall ambient sound when trying to ascertain the influence of speech intelligibility on observed and perceived disturbance during the performing of a mental activity. Insights are provided which could lead to the use of a speech intelligibility measure better equipped to deal with multi-sources environments.

Published by the Acoustical Society of America through the American Institute of Physics 


\section{INTRODUCTION}

In open-plan offices, partitioning screens do not go all the way up to the ceiling. Such architectural choices make communication between employees much easier. However, the ambient noise can be particularly distracting (Brookes and Kaplan, 1972). Speech noise is thus often reported as being one of the most important causes for disturbance for employees in open-plan offices (Nemecek and Grandjean, 1973). Moreover, the intelligibility of speech seems to be a crucial factor: people complain more when clear and distinct voices can be singled out from an ambient babble (Sundstrom et al., 1980).

These observations are borne out by the results of studies of work performance in laboratory settings. The presence of background noise can indeed impair one's work performance (Hughes and Jones, 2001). This phenomenon is called irrelevant sound effect (ISE). Performance in laboratory settings can be markedly sensitive to the presence of background speech. When speech intelligibility is altered, either with decreasing signal-to-noise ratios or by low-pass filtering, the original performance level is progressively restored (Banbury et al., 2001).

Intelligibility measures thus appear to be well-suited to quantify the nuisance potential of a sound environment rich with speech sounds. As such, the Speech transmission index (STI) has already been used in a predictive model of decrease in performance due to ambient speech (Hongisto, 2005; Ebissou et al., 2012). From this model, target values have been formulated in the international standard ISO 3382-3 (2012) in order to assess the acoustical quality of an open-plan office .

The goal of the present work was to evaluate the predictive power of the STI on noise annoyance in multipletalker environments that resemble realistic ambient sounds in open-plan offices. The first experiment simulated a situation in which the voice of a close neighbour emerges from an unintelligible babble. The second experiment allowed for the possible presence of several close neighbours, whose voices can be clearly heard but still be masked by the others. Noise annoyance was assessed both through an objective measure of performance and a self-reporting of mental workload.

\section{FIRST EXPERIMENT: STATIONARY BACKGROUND BABBLE}

\section{Methods}

Fifty-seven participants ( 32 women, 25 men; aged 22 to 73 years old, mean age: 36 years old) were presented with a seriation task. The nine digits between 1 and 9 were displayed on a computer screen one by one every second in a random order. After a 5-second pause, a 3x3 array with the nine digits in the usual order appeared on the screen (MS Sans Serif font, 85 points). Subjects then were asked to reproduce the original order of the series. No time limit was implemented, but it was not possible to go back on a proposed digit. Once the answer as entirely given, a new series began. The task was divided in 10-minutes blocks. The experiment took place in a sound-proofed cabin. During each block, only one of the five following sound conditions was encountered:

- $\quad$ Silence (STI =0),

- $\quad$ Emerging voice in babble, $\mathrm{STI}=0.25$,

- $\quad$ Emerging voice in babble, $\mathrm{STI}=0.35$,

- $\quad$ Emerging voice in babble, $\mathrm{STI}=0.45$,

- $\quad$ Emerging voice in babble, $\mathrm{STI}=0.65$.

The voice excerpts and the accompanying babble noises originated from lists of sentences recorded for audiometry purposes. A simple model of the acoustics of open-plan offices was used to attain the different STI values (Hongisto et al., 2004). The overall long-term average sound level was set at $46 \mathrm{~dB}(\mathrm{~A})$.

In order to allow for possible learning effects and avoid exertion, the experiment was divided in two 1-hour sessions for each participant, on consecutive days. Each session comprised two "noisy" blocks and a silent reference. The order in which subjects faced the conditions was balanced over the participants. The decrease in performance was computed as the difference between the mean error rates in the studied condition and the silent reference. Each noisy block was compared with the reference block that was carried out in the same session. Moreover, at the end of each block, participants had to complete a NASA-TLX questionnaire in order to assess the mental workload they underwent. The questionnaire, regularly used in cognitive load studies, consists of 6 questions 
addressing different aspects of the mental workload (Hart and Staveland, 1988). For each question, a score from 0 to 100 is reported; the lower the score, the easier the task. A Raw Task Load Index (RTLX) is eventually computed by averaging the scores.

\section{Results}

The data presented a hierarchical structure: blocks were carried out on a given session by a given subject. Strong within-subject and within-session correlations were expected. Therefore, a three-level mixed-effects regression model was used. The raw results tend to show that performances decrease as speech intelligibility increases as shown in figure 1(a). Indeed, subjects averaged 2.25 errors per series in silence and 2.71 errors when STI $=0.65$. However, the effect of the STI value was not great enough to be significant. The STI value explained only $2 \%$ of the total observed variance. On the other hand, the between-subject variability explained $51.5 \%$ of total variance.

(a)

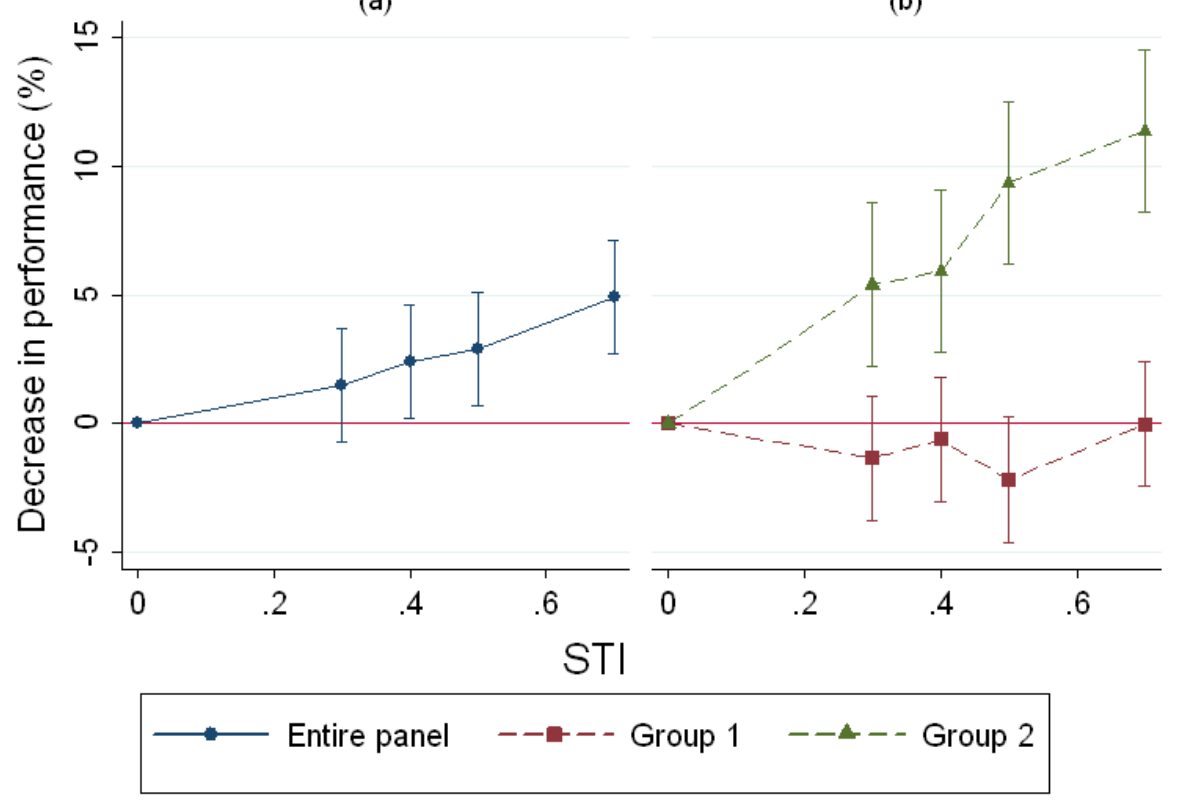

FIGURE 1. Mean decrease in performance for each STI value (a) for the entire panel of participants, (b) for each of the two sensitivity groups, with $95 \%$ confidence intervals.

A cluster analysis was thus undertaken in order to see whether groups with different sensitivity to STI could be identified. It indeed appeared that the 59-subject panel could be divided into 2 categories, as one can see in figure 1(b). The 32 subjects of the first one do not, in average, exhibited any significant sensibility to ambient speech intelligibility. On the contrary, for the 25 subjects in the second group, the neighbouring speaker had a negative influence on performance as soon as the STI reaches 0.25 , and this impact strengthened as the STI rose. 


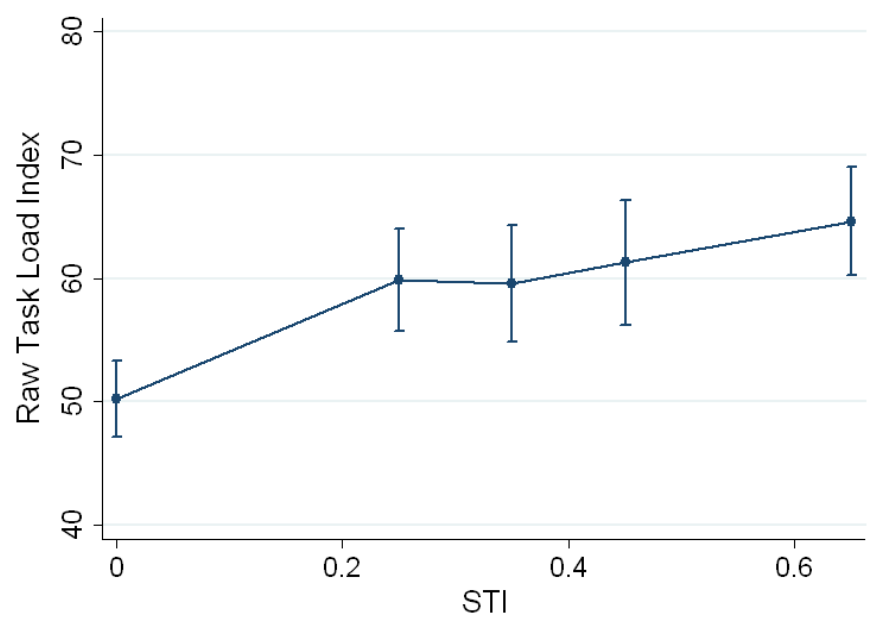

FIGURE 2. Mean Raw Task Load Index for each STI value, with 95\% confidence intervals.

Mental workload, as measured by the NASA-RTLX and thus displayed in figure 2, also increased with better speech intelligibility. Here, the effect the STI was significant for the entire group. The value of the intelligibility index explained $9.1 \%$ of the total variance. Moreover, the two groups previously defined did not exhibit fundamentally different response patterns with regards to variations in ambient speech intelligibility. A finer analysis of the answers to each question showed that increasing speech intelligibility led subjects to increase their effort level, but still made them see their performance level as decreasing.

\section{SECOND EXPERIMENT: LIMITED NUMBER OF TALKERS}

In the previous experiment, the masking babble was made up of a large number of voices so as to render its level stationary. However, in open-plan offices, one can be surrounded by a few close neighbours who can speak simultaneously. In that case, relative to a given voice, the background noise level cannot always be described as stationary. The fluctuations in masking noise level are known to have an impact on speech intelligibility that is not well accounted for by the STI (Chevret et al., 2012). It remained to be seen whether this effect can be seen on speech-induced noise annoyance.

\section{Methods}

Thirty-one subjects agreed to participate in this experiment ( 8 men, 23 women, aged 18 to 32 years old, mean: 23 years old). It should be noted that in the previous experiment, no significant effect of age and sex had been found. The task is similar to the previous one, save for one change: in order to study the effects of the sound condition on the temporal demands of the task, the response time was limited to 13 seconds. The duration of a display-pauseanswer cycle for one series of digits therefore consistently equalled 30 seconds. As such, any digit a subject did not have time to input was counted as an additional error.

The sound conditions were composed by mixing a male voice with interfering female voices in varying number:

- 1 male voice, 1 female voice (noted $\mathrm{M}+1 \mathrm{~F})$,

- 1 male voice, 3 female voices $(\mathrm{M}+3 \mathrm{~F})$,

- 1 male voice, 5 female voices $(\mathrm{M}+5 \mathrm{~F})$,

- 1 male voice, stationary noise $(\mathrm{M}+\mathrm{SN})$.

For the subsequent remarks on speech intelligibility, the male voice was considered as the "target". The average level and spectrum of the overall masking noise were kept constant over all conditions, so that the STI value always equalled 0.4 for all conditions. Thus, the intelligibility of the target voice was expected to increase as the number of interfering voices diminished, as it was then possible to "listen in the gaps" (Bronkhorst, 2000). The reference condition was changed from silence to a stationary noise which long-term average spectrum was similar to the one 
encountered in the speech conditions. The overall long-term average sound level was set at $46 \mathrm{~dB}(\mathrm{~A})$. Otherwise, the overall proceeding of the experiment was unchanged from the previous one.

\section{Results}

As with the previous experiment, a three-level mixed-effects regression model was used to analyse the results.

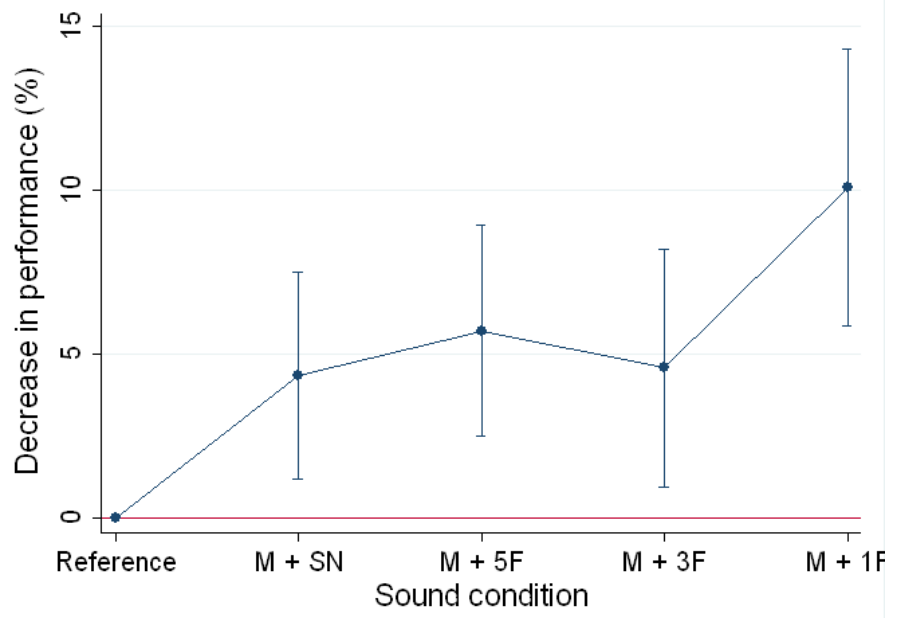

FIGURE 3. Mean decrease in performance for each sound condition, with $95 \%$ confidence intervals

It appeared that the target voice intelligibility had an influence on performance: 2.10 errors in average were committed per series in the reference condition, but that number rose to 2.85 when a single voice interfered with the target. The sound condition factor had a significant effect. More specifically, as one can see in figure 3 , the $\mathrm{M}+1 \mathrm{~F}$ condition was significantly more disturbing than the other three speech conditions. Nevertheless, the sound condition factor explained only $4.4 \%$ of the total variance, whereas between-subject variability accounted for $58.2 \%$ of it. No clear clustering of the panel could be obtained.

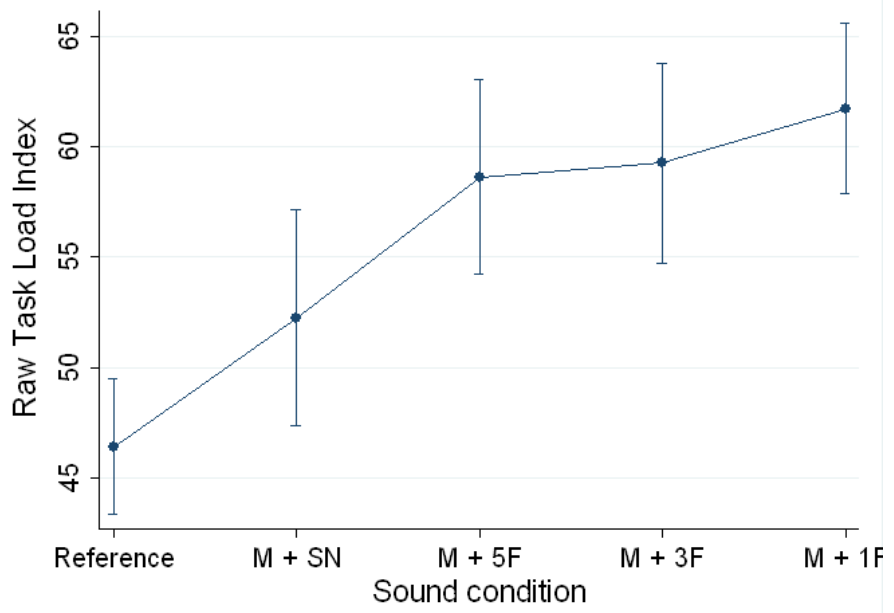

FIGURE 4. Mean Raw Task Load Index for each sound condition, with 95\% confidence intervals.

The RTLX values presented in figure 4 indicate that from a mental workload perspective, there was a clear difference between the conditions comprising interfering voices and the ones where stationary noise could be found. The effect of sound condition was indeed significant. Moreover, simply adding the male voice to the stationary noise sufficed to create a significant increase in mental workload. The sound condition factor explained, by itself, $19.8 \%$ of the total variance. A finer analysis of the questionnaire showed that an increase in speech intelligibility exacerbated the time pressure endured during the task, as well as the effort level it required and the level of frustration they felt. They also saw their performance as being impaired by increased speech intelligibility. 


\section{CONCLUSION}

The effect of multi-talker office-like environments on noise annoyance was investigated in this paper. It appeared that, as expected, speech intelligibility was an important factor in increasing the difficulty of a given task. Nevertheless, a widely-used intelligibility index such as the STI did not appeared to be a good predictor of performance. Background sound level fluctuations, for example, seemed to have approximately twice the explanatory power. Future attempts at objectively predicting the nuisance potential of sound environments rich in speech sounds should allow for this phenomenon.

The same discrepancy in explaining power is also true for the mental workload, as measured by the Raw Task Load Index. This measure, widely used in the mental workload literature, was more sensitive to changes in intelligibility and more robust with respect to between-subject variability than the performance measure. Such alternative measurements of task difficulty in conjunction with usual performance measures should therefore be systematic when trying to assess noise annoyance in a work environment.

\section{REFERENCES}

Banbury, S. P., Macken, W. J., Tremblay, S., and Jones, D. M. (2001). "Auditory distraction and short-term memory: Phenomena and practical implications," Human Factors: The Journal of the Human Factors and Ergonomics Society 43, 12.

Bronkhorst, A. W. (2000). "The cocktail party phenomenon: A review of research on speech intelligibility in multiple-talker conditions," Acustica - Acta Acustica 86, 117-128.

Brookes, M. J., and Kaplan, A. (1972). "The office environment: space planning and affective behavior," Human Factors: The Journal of the Human Factors and Ergonomics Society 14, 373-391.

Chevret, P., Ebissou, A., and Parizet, E. (2012). "Evaluation of speech intelligibility in open-plan offices," in INTER-NOISE and NOISE-CON Congress and Conference Proceedings, pp. 5532-5544.

Ebissou, A., Chevret, P., and Parizet, E. (2012). "Objective and subjective assessment of disturbance by office-noise - Relevance of the use of the speech transmission index," in Proceedings of Acoustics 2012 - 1lème Congrès Français d'Acoustique, 2012 Annual IOA Meeting (Nantes, France).

Hart, S. G., and Staveland, L. E. (1988). "Development of NASA-TLX (Task Load Index): Results of empirical and theoretical research," in Human Mental Workload, edited by P. Hancock, and N. Meshkati (North Holland, Amsterdam), pp. 139183.

Hongisto, V. (2005). "A model predicting the effect of speech of varying intelligibility on work performance," Indoor Air 15, 458-468.

Hongisto, V., Keranen, J., and Larm, P. (2004). "Simple model for the acoustical design of open-plan offices," Acta Acustica united with Acustica 90, 481-495.

Hughes, R., and Jones, D. M. (2001). "The intrusiveness of sound : Laboratory findings and their implications for noise abatement," Noise \& Health 4, 51-70.

International Organization for Standardization (2012). ISO 3382-3 Acoustics - Measurement of room acoustic parameters (International Organization for Standardization)

Nemecek, J., and Grandjean, E. (1973). "Noise in landscaped offices," Applied Ergonomics 4, 19-22.

Sundstrom, E., Burt, R. E., and Kamp, D. (1980). "Privacy at work: Architectural correlates of job satisfaction and job performance," Academy of Management Journal 23, 101-117. 